\title{
Spectrophotometeric Determination of Ponceau 4R in the Several Beverages Using Mixed Micelles after Cloud Point Extraction
}

\author{
Mohammed Z. Thani ${ }^{*}$, Salam A.H. Al-Ameri and Muntadhar Salih Sultan \\ ID Orcid / 0000-0003-0463-8928, 0000-0001-5495-9549, 0000-0002-0122-9128 \\ Department of Chemistry, College of Science, Al-Mustansiriyah University, Baghdad-Iraq. \\ *Corresponding Author: Mohammed.chem@uomustansiriyah.edu.iq.
}

\begin{abstract}
Ponceau $4 \mathrm{R}(\mathrm{E} 124)$ is azo dye that is mostly used in some of food products such as soft drinks, beverages, jelly and ham. A simple and sensitive procedure is established for the determination of ponceau $4 \mathrm{R}$ using cloud point extraction (CPE). In order to get the optimum conditions for ponceau 4R extraction, various analytical factors such as $\mathrm{pH}$ media, nonionic surfactant TX-114 or Brij-56, cationic surfactant CPC and equilibration temperature was investigated. The linearity of calibration graph was above the range of $0.05-1.7 \mu \mathrm{g} \mathrm{ml}^{-1}$. The LOD and LOQ using TX-114 were based to be $0.025,0.075 \mu \mathrm{g} \mathrm{ml}^{-1}$ whereas for Brij-56 were found as $0.062,0.187 \mu \mathrm{g} \mathrm{ml}^{-1}$ respectively. The proposed procedure was successfully employed for ponceau $4 \mathrm{R}$ detection in several beverages samples. [DOI: 10.22401/JUNS.21.1.02]
\end{abstract}

Keywords: Cloud point extraction, Ponceau 4R, Beverage.

\section{Introduction}

The ponceau $4 \mathrm{R}(\mathrm{E} 124)$ as an azo dye food, is widely added into soft drinks, beverages, sweets, ham and jelly to make it more engaging $[1,2]$. The chemical structure of the ponceau $4 \mathrm{R}$ (E124) is given in Fig.(1). The $\mathrm{N}=\mathrm{N}$ azo group and aromatic ring in the structure of azo dyes make it harmful to human health when adding large amounts of these dyes[3]. New methods are employed for pre-concentration and evaluation of azo dye such as solid-phase extraction (SPE) [4, 5], cloud point extraction $[6,7]$, dispersive liquidliquid micro-extraction; as well as estimation techniques for examples differential pulse polarography [8], spectorphotometry $[3,9,10]$ and chromatographic methods [11-14]. The CPE method has several advantages such as fast, low cost and safety, therefore, it has employed as one of the evaluation and preconcentration procedures in analytical chemistry. In this study, CPE method has been developed using mixed of nonionic surfactant TritonX-114 or Brij-56 with cationic surfactant cetyl pyridinium chloride and used for the pre-concentration and spectrophotometric determination of ponceau $4 \mathrm{R}$ in several beverage samples. The influence of $\mathrm{TX}-114, \mathrm{CPC}$ and $\mathrm{NaCl}$ concentrations, equilibrium temperature and incubation time on the performance of CPE was investigated.

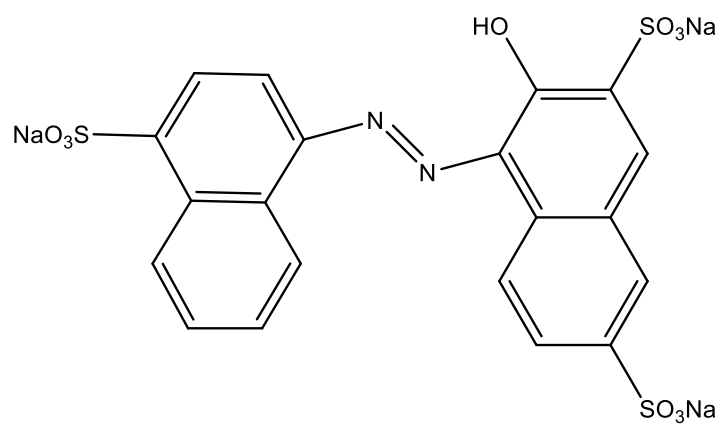

Fig.(1): Chemical Structure of Ponceau 4R [Sodium(E)-3-OH-4-((4-

Sulfonatonaphthalen-1-yl)diazenyl) naphthalene-2,7-disulfonate].

\section{Experimental \\ Reagent and solutions}

The chemicals used in this work were analytical grade. A stock solution $1000 \mu \mathrm{g} \mathrm{ml}^{-1}$ of ponceau 4R(M.wt $604.08 \mathrm{~g} \mathrm{~mol}^{-1}$ ) SigmaAldrich was prepared by dissolving $0.1 \mathrm{gm}$ of pure dye and diluted to $100 \mathrm{ml}$ with distilled water. More dilute solutions of ponceau 4R were daily prepared via successive dilutions with distilled water as required. A $0.5 \mathrm{M}$ of TX-114(M.wt $537 \mathrm{~g} \mathrm{~mol}^{-1}$ ) or Brij-56(M.wt $682 \mathrm{~g} \mathrm{~mol}^{-1}$ ) solutions were prepared by dissolving $26.85 \mathrm{gm}$ of TX-114 and $34.15 \mathrm{gm}$ of Brij-56 in 100 volumetric flask and completed the volume to the mark with D.W. A $0.01 \mathrm{M}$ cetylpyridinium chloride CPC (M.wt 
$339.992 \mathrm{~g} \mathrm{~mol}^{-1}$ ) sigma-aldrich solution was prepared by dissolving accurately weighted $0.358 \mathrm{gm}$ of pure compound in $100 \mathrm{ml}$ of D.W. Hydrochloric acid and sodium hydroxide solutions were used to prepare the buffer solutions and adjusting to required $\mathrm{pH}$. Sodium chloride solution $2 \mathrm{M}$ was prepared by dissolving $11.68 \mathrm{gm}$ of $\mathrm{NaCl}$ in $100 \mathrm{ml}$ D.W.

\section{Instruments}

A cintra-5 UV-Vis spectrophotometer (Australia) with a $1 \mathrm{~cm}$ quartz cell was employed to measure the absorbance of ponceau 4R (E124) at $507 \mathrm{~nm}$. The $\mathrm{pH}$ values were recorded by metler $\mathrm{pH}$ meter. Human Lab model DWB-22 Korea, water bath was used for heating.

\section{General procedure}

In a suitable and graduated test tube with plastic stopper, an aliquot solution of ponceau 4R was taken, then $2 \mathrm{ml}$ of $0.5 \mathrm{M}$ TX-114 or Brij-56 was added, also $1 \mathrm{ml}$ of $\mathrm{pH}=3$ buffer solution, $0.2 \mathrm{ml}$ of $0.01 \mathrm{M} \mathrm{CPC}$ and $0.75 \mathrm{ml}$ of $2 \mathrm{M} \mathrm{NaCl}$ solution for TX-114 and $1 \mathrm{ml}$ of $2 \mathrm{M} \mathrm{NaCl}$ for Brij-56 was added. The mixture was diluted to $10 \mathrm{ml}$ with D.W. The mixture solution was shaken and heated in a thermostatic bath at $50^{\circ} \mathrm{C}$ for 20 min with TX114 and $70^{\circ} \mathrm{C}$ for $30 \mathrm{~min}$ with Brij-56; the mixture was cooled in an ice bath, the aqueous phase and surfactant-rich phase was easily separated by decantation. Surfactant-rich phase was analyzed after diluted with D.W to $5 \mathrm{ml}$ and measure the absorbance at $507 \mathrm{~nm}$.

\section{Results and Discussion}

In order to get quantitative recoveries of ponceau $4 \mathrm{R}$ by $\mathrm{CPE}$ procedure, the enrichment/ separation method was investigated at several analytical factors such as nonionic surfactant TX-114 or Brij-56 concentration, cationic surfactant CPC concentration, influence of the equilibrium temperature and incubation time. The absorbance of ponceau 4R after CPE was found and recorded at $507 \mathrm{~nm}$.

\section{Effect of $p H$}

The $\mathrm{pH}$ was the first factor predestined on the determination of ponceau 4R. The effect of $\mathrm{pH}$ value on the CPE performance of ponceau $4 \mathrm{R}$ was inspected in extent from $\mathrm{pH} 1$ to 8 using sodium hydroxide and hydrochloric acid solutions. The best of extraction efficiencies was obtained at $\mathrm{pH} 3$, Fig.(2). Therefore, $\mathrm{pH} 3$ was selected in this work. Various buffer solutions was studied such as; citrate, acetate and buffer solution $(\mathrm{NaOH}-\mathrm{HCl})$. The last buffer solution was chosen for this work because, it gives a good extract in this method. Thus, $1 \mathrm{ml}$ buffer solution $\mathrm{pH} 3$ was added to the solutions in the subsequent experiments.

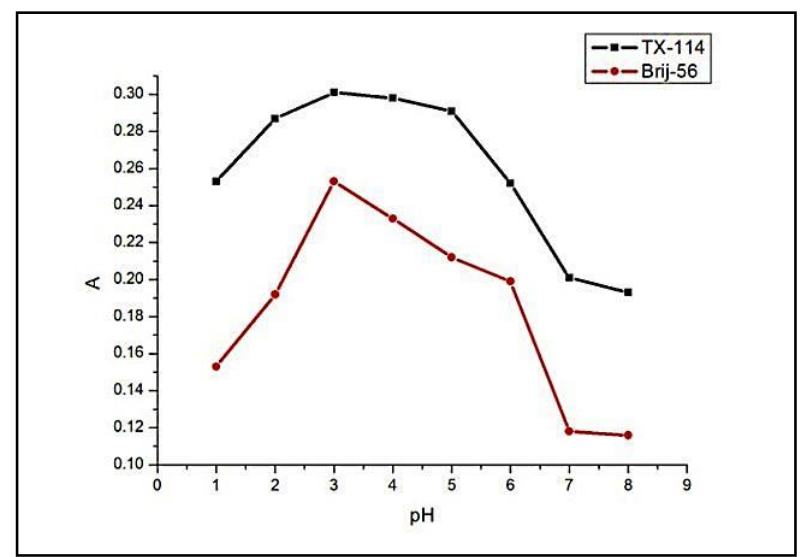

Fig.(2): Effect of $\mathrm{pH}$ on the CPE extraction of Ponceau 4R using TX-114 and Brij-56.

\section{Effects of nonionic surfactant amount}

The influence of TX-114 or Brij-56 surfactant concentration on the extraction efficiency was investigated. Surfactant concentration was studied in the range between $5 \times 10^{-3}-2 \times 10^{-1} \mathrm{M}$. The result illustrate that the absorbance will increases with surfactant concentration increasing, therefore, $1 \times 10^{-1} \mathrm{M}$ was chosen for this work, Fig.(3).

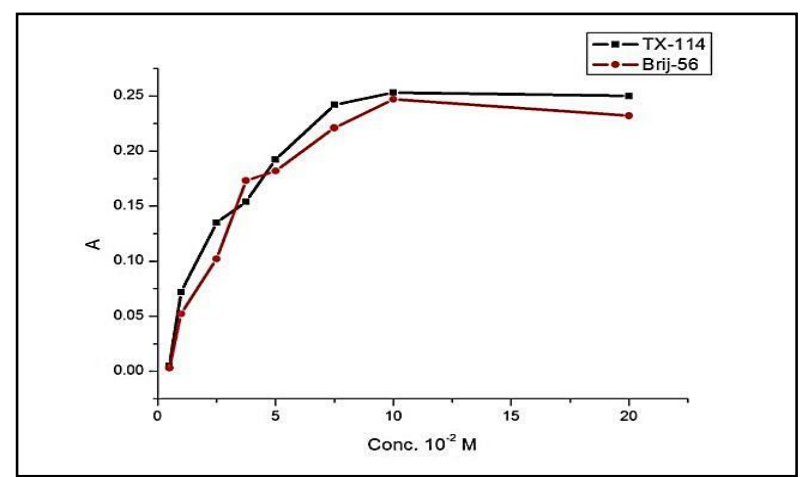

Fig.(3): Effect of TX-114 and Brij-56 surfactant concentration on CPE of Ponceau $4 R$.

Effects of cationic surfactant amounts

Cloud point extraction of ponceau $4 \mathrm{R}$ is more efficient in there of cationic surfactant CPC. Therefore, the influence of CPC concentration on performance $\mathrm{CPE}$ and 
determination of ponceau $4 \mathrm{R}$ was investigated in the range between $2 \times 0^{-5}-1 \times 10^{-3} \mathrm{M}$. Ponceau 4R formed an ion pair with $\mathrm{CPC}$ and extracted to nonionic surfactant TX-114 or Brij-56. The results showed that the absorbance of solution will decrease without adding CPC and increase with increasing of CPC concentration up to $2 \times 10^{-4} \mathrm{M}$, thus, this concentration of CPC was chosen as optimum Fig.(4).

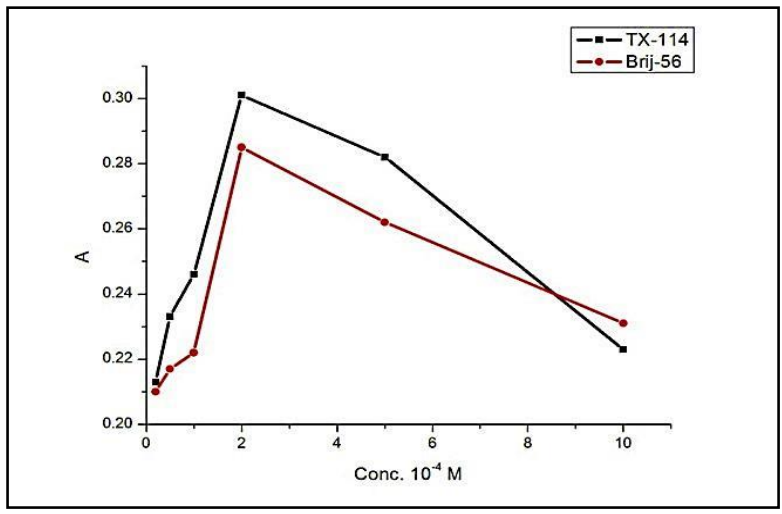

Fig.(4): Effect of CPC on the cloud point extraction of Ponceau $4 R$.

\section{Effect of salt concentration}

The efficiency of CPE method will increase when adding an electrolyte [15]. To confirm the effect of $\mathrm{NaCl}$ concentration on the extraction efficiency of ponceau $4 \mathrm{R}$, the results observed in Fig.(5) prove that $0.15 \mathrm{M}$ and $0.2 \mathrm{M}$ were chosen as aptimum for TX-114 and Brij-56 respectively

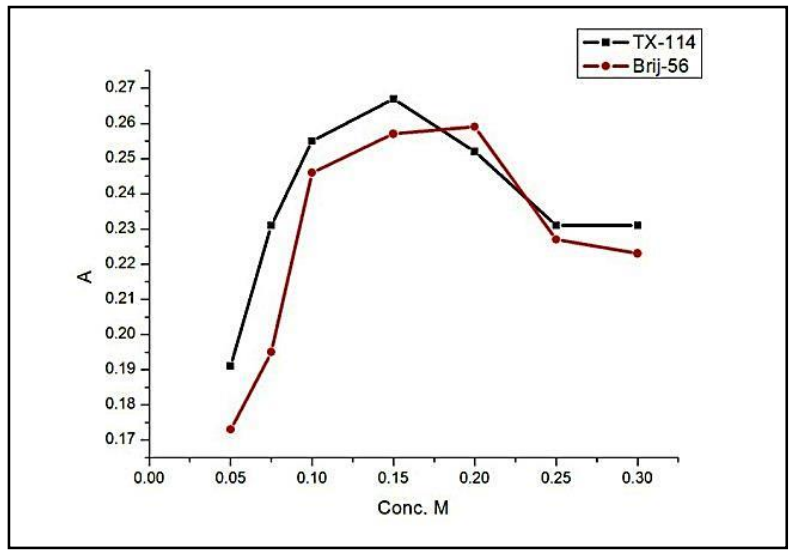

Fig.(5): Effect of $\mathrm{NaCl}$ concentration on the CPE of Ponceau 4R.

\section{Effects of equilibrium temperature and Incubation time}

The optimum equilibrium temperature and incubation time are requisite to complete the extraction, and to get easy phase separation and pre-concentration as much as possible efficiency. This method was desirable to use the lowest equilibrium temperature and the shortest equilibration time, which compromise accomplishment of the extraction and separation efficiency of phases. The influence of equilibrium temperature in the range between $10-80^{\circ} \mathrm{C}$ was investigated. The result showed that $50^{\circ} \mathrm{C}$ for $\mathrm{TX}-114$ and $70^{\circ} \mathrm{C}$ for Brij-56 were the best and chosen as optimum temperature. The incubation time was studied in the range 10-50 $\mathrm{min}$. It was found that 20 min for TX-114 and 30 min for Brij-56 were the finest time and selected for this work.

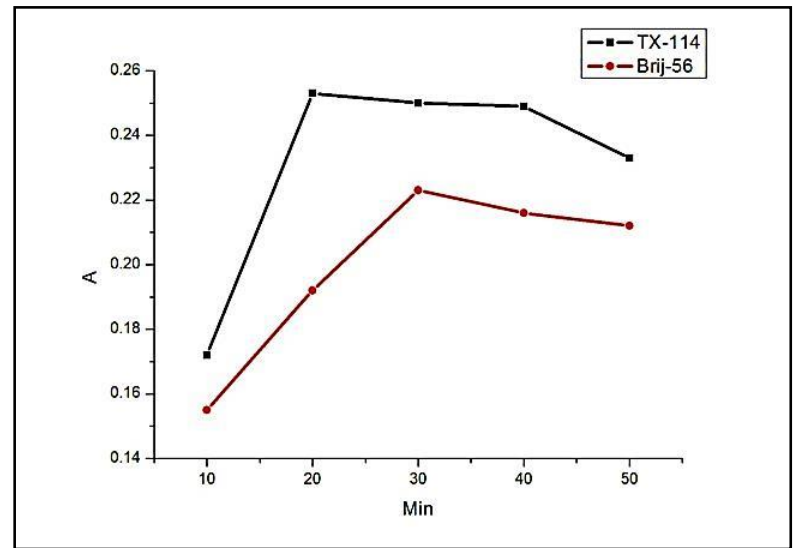

Fig.(6): Effect of incubation time on the CPE of Ponceau 4R.

\section{Analytical performance}

From the measurements completed throughout the optimal various parameters described above, the calibration graph was linear in the range 0.05-1.7 $\mu \mathrm{g} \mathrm{ml}^{-1}$. The graphical appearance of the absorbance plot obtained for Ponceau 4R against the concentration is given in the Fig.7 and 8 . The LOD and LOQ was found as $0.025,0.075 \mu \mathrm{g}$ $\mathrm{ml}^{-1}$ for TX-114 and 0.06, $0.187 \mu \mathrm{g} \mathrm{ml}^{-1}$ for Brij-56, respectively. The statistical analytical number of the proposed method are summarized in Table (1). 
Table (1)

Analytical data of the Evaluation of Ponceau $4 R$ by proposed cloud point extraction procedure.

\begin{tabular}{|c|c|c|}
\hline Parameter & TritonX-114 & Brij-56 \\
\hline$\Lambda_{\max } \mathrm{nm}$ & \multicolumn{2}{|c|}{507} \\
\hline Equation & $\begin{array}{c}\mathrm{Y}=0.429 \mathrm{X}- \\
0.027\end{array}$ & $\begin{array}{c}\mathrm{Y}=0.253 \mathrm{X}+ \\
0.001\end{array}$ \\
\hline $\begin{array}{l}\text { Correlation } \\
\text { Coefficient(r) }\end{array}$ & 0.9996 & 0.9997 \\
\hline $\begin{array}{l}\text { Concentration } \\
\text { range }\left(\mu \mathrm{gml}^{-1}\right)\end{array}$ & $0.05-1.7$ & $0.05-1.7$ \\
\hline Slope & 0.429 & 0.253 \\
\hline Intercept & 0.027 & 0.001 \\
\hline $\begin{array}{l}\text { Molar absorpitivity } \\
\text { L. } \mathrm{mol}^{-1} \cdot \mathrm{cm}^{-1}\end{array}$ & $25 \times 10^{4}$ & $17 \times 10^{4}$ \\
\hline Sandells sensitivity & 0.00241 & 0.00355 \\
\hline $\begin{array}{c}\text { Standared deviation } \\
(\mathrm{S})\end{array}$ & 0.003 & 0.004 \\
\hline $\operatorname{LOD}\left(\mu \mathrm{gml}^{-1}\right)$ & 0.025 & 0.062 \\
\hline$\overline{\mathrm{LOOQ}}\left(\mu \mathrm{gml}^{-1}\right)$ & 0.075 & 0.187 \\
\hline
\end{tabular}

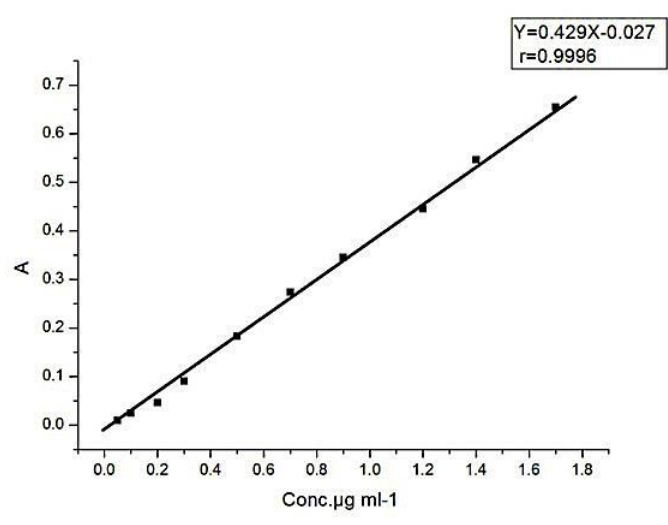

Fig.(7): Calibration graph of E124 at concentration range 0.05-1.7 $\mathrm{gmml}^{-1}$ in $\mathrm{TX}-114$.

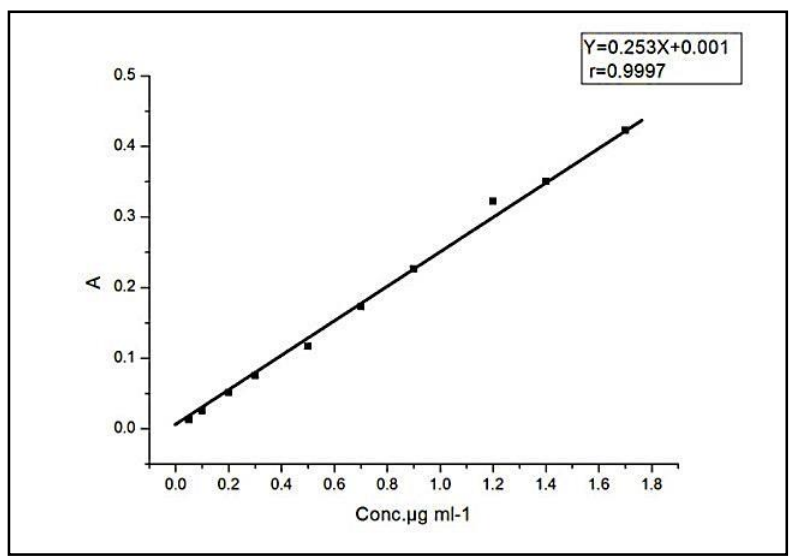

Fig.(8): Calibration graph of E124 at concentration range 0.05-1.7 $\mu^{-1} \mathrm{gl}^{-1}$ in Brij-56.

Table (2)

Comparison the values of LOD of the proposed method with different methods reported in literature.

\begin{tabular}{||c||c|c||}
\hline Method & LOD $\boldsymbol{\mu g} \boldsymbol{~ m l}^{-1}$ & Ref. \\
\hline \hline EGPE & 0.001 & {$[1]$} \\
\hline \hline HPLC & 0.002 & {$[16]$} \\
\hline HPLC & 0.052 & {$[17]$} \\
\hline $\begin{array}{c}\text { LCET mass } \\
\text { spectrometry }\end{array}$ & 0.125 & {$[18]$} \\
\hline \hline SPE & $2 \times 10^{-5}$ & {$[19]$} \\
\hline \hline HPLC & 2 & {$[20]$} \\
\hline HPLC & 0.088 & {$[21]$} \\
\hline \hline CPE & $0.025,0.062$ & Present work \\
\hline \hline
\end{tabular}


Table (3)

Application of the proposed CPE method for the determination Pomceau 4R (E124).

\begin{tabular}{|c|c|c|c|c|c|c|c|c|}
\hline \multirow[b]{2}{*}{ Sample } & \multicolumn{4}{|c|}{ TritonX-114 } & \multicolumn{4}{|c|}{ Brij-56 } \\
\hline & $\begin{array}{c}\text { E124 add } \\
\left(\mu g m l^{-1}\right)\end{array}$ & $\begin{array}{c}\text { E124 } \\
\text { found } \\
\left(\mu g m l^{-1}\right)\end{array}$ & $R S D \%$ & Recovery\% & $\begin{array}{c}\text { E124 add } \\
\left(\mu g m l^{-1}\right)\end{array}$ & $\begin{array}{l}\text { E124 found } \\
\quad\left(\mu g m l^{-1}\right)\end{array}$ & $R S D \%$ & Recovery\% \\
\hline \multirow{3}{*}{ Beverage 1} & - & $0.35 \pm 0.0 .02$ & 5.7 & - & - & $0.25 \pm 0.029$ & 10.3 & - \\
\hline & 0.2 & $0.52 \pm 0.01$ & 1.9 & 94 & 0.2 & $0.38 \pm 0.009$ & 2.6 & $\Lambda \varepsilon$ \\
\hline & 0.3 & $0.64 \pm 0.01$ & 1.5 & 98 & 0.3 & $0.65 \pm 0.019$ & 3.2 & 17 \\
\hline $\begin{array}{c}\text { Beverage } 1 \\
\text { Without } \\
\text { CPC }\end{array}$ & - & $0.30 \pm 0.008$ & 2.3 & - & - & $0.20 \pm 0.009$ & 4.9 & - \\
\hline \multirow{3}{*}{ Beverage 2} & 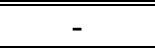 & $0.53 \pm 0.004$ & 0.5 & 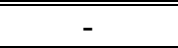 & 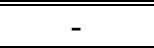 & $0.41 \pm 0.010$ & 2.6 & 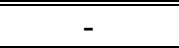 \\
\hline & 0.2 & $0.71 \pm 0.012$ & 1.5 & 97 & 0.2 & $0.54 \pm 0.009$ & 1.8 & 11 \\
\hline & 0.3 & $0.81 \pm 0.016$ & 1.8 & 91 & 0.3 & $0.61 \pm 0.011$ & 2.1 & 14 \\
\hline $\begin{array}{c}\text { Beverage } 2 \\
\text { Without } \\
\text { CPC }\end{array}$ & - & $0.49 \pm 0.002$ & 0.4 & - & - & $0.32 \pm 0.011$ & 4.1 & - \\
\hline \multirow{3}{*}{ Beverage 3} & 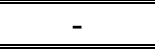 & $0.46 \pm 0.003$ & 0.8 & 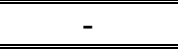 & 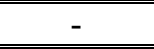 & $0.32 \pm 0.011$ & 3.9 & - \\
\hline & 0.2 & $0.64 \pm 0.028$ & 3.8 & 96 & 0.2 & $0.42 \pm 0.009$ & 2.4 & 78 \\
\hline & 0.3 & $0.71 \pm 0.016$ & 2.0 & 94 & 0.3 & $0.54 \pm 0.010$ & 2.0 & 17 \\
\hline $\begin{array}{c}\text { Beverage } 3 \\
\text { Without } \\
\text { CPC }\end{array}$ & - & $0.35 \pm 0.022$ & 5.6 & - & - & $0.23 \pm 0.022$ & 10.5 & - \\
\hline \multirow{3}{*}{ Beverage 4} & - & $0.75 \pm 0.022$ & 5.6 & - & - & $0.61 \pm 0.004$ & 0.8 & - \\
\hline & 0.2 & $0.94 \pm 0.010$ & 0.9 & 98 & 0.2 & $0.71 \pm 0.010$ & 1.4 & 87 \\
\hline & 0.3 & $0.99 \pm 0.010$ & 0.9 & 94 & 0.3 & $0.78 \pm 0.001$ & 0.2 & 86 \\
\hline $\begin{array}{c}\text { Beverage } 4 \\
\text { Without } \\
\text { CPC }\end{array}$ & - & $0.63 \pm 0.029$ & 4.0 & - & - & $0.53 \pm 0.010$ & 2.0 & - \\
\hline
\end{tabular}

\section{Application}

Ponceau $4 \mathrm{R}$ that presence in a various beverage samples 1, 2, 3 and 4 was estimation and pre-concentration by proposed CPE procedure. The recovery was performed for the samples by determination the ponceau $4 \mathrm{R}$ after adding known amounts of the analyte. The results and analytical data showed in the table 3 confirm a good accuracy, precision and recoveries for ponceau $4 \mathrm{R}$ determination using developed CPE method.

\section{Conclusion}

A simple, ecological-friendly, precise, accurate and pre-concentration $\mathrm{CPE}$ procedure for evaluation of ponceau $4 \mathrm{R}$ has been developed. The procedure is less time consulting and cheap compared with the other methods such as HPLC, SPE and liquid-liquid extraction. The method gives a useful enrichment technique in the different samples with reasonable precision and accuracy.

\section{References}

[1] Zhang J., Wang M., Shentu C., Wang W. and Chen Z., "Simultaneous determination of the isomers of ponceau 4R and Amaranth using an expanded graphite paste electrode", Food Chemistry, 160, 11-15, 2014.

[2] Yang Y., Yin I. and Shao B., "Simultaneous determination of five aluminium lake dyes in chewing gum by HPLC with photodiode array detection", Food Additives and Contaminants, 28, 1159-1167, 2011.

[3] Ozdemir Y. and Akkan A., "Determination of Patent Blue $\mathrm{V}$ and Carmoisine in Gelatine Desserts By Derivative Spectrophotometry", Turk J. Chem., 23, 221- 229, 2009.

[4] Al-degs Y., El-sheikh A.H., Al-ghouti M. A., Hemmateenejad B. and Walker G., "Solid - phase extraction and simultaneous determination of trace amounts of sulphonated and azo sulphonated dyes using 
microemulsion-modified-zeolite and multivariate calibration", Talanta,75, 904915, 2008.

[5] Vinod K., Gupta A. M. and Jyoti M., "Adsorption of carmoisine A from wastewater using waste materials-Bottom ash and deoiled soya", J. Colloid Interf. Sci., 335, 24-33, 2009.

[6] Pourreza N. and Ghomi M., "Simultaneous cloud point extraction and spectrophotometric determination of carmoisine and brilliant blue FCF in food samples", Talanta , 84, 240-243, 2011.

[7] Pourreza A. and Zareian M., "Determination of Orange II in food samples after cloud point extraction using mixed micelles", 165, 1124-1127, 2009.

[8] Fogg A. G. and Summan A. M., "The Analyst", Royal society of chemistry, 109, 743-747, 1984.

[9] Rouhollah H., Mohammad H., Mohammad A. and Sanaz Z., "A Simple Method for Simultaneous Spectrophotometric Determination of Brilliant Blue FCF and Sunset Yellow FCF in Food Samples after Cloud Point Extraction", J.Chem.Soc.Pak., 38, 03, 438-445, 2016.

[10] Amandeep K., Usha G., "The Review on Spectrophotometric Determination of Synthetic Food Dyes and Lakes", Gazi University J. Science, 25(3), 579-588, 2012.

[11] Rizova V., Stafilov T. and Stojanovski K., "HPLC investigation of the degradation of some artificial food colorant in the presence of ascorbic acid", Acta Pharm., 49, 211216, 1999.

[12] Nevado J. J. B., Cabanillas C. G. and Salcedo C. A. M., "A Reverse Phase HPLC Method to Determine Six Food Dyes Using Buffered Mobile Phase", Anal. Lett., 31, 2513- 2535, 1998.

[13] Vachirapatama N., Mahajaroensiri J. and Visessanguan W., "Identification and Determination of Seven Synthetic Dyes in Foodstuffs and Soft Drinks on Monolithic C18 Column by High Performance Liquid Chromatography", J. Food and Drug Anal., 16, 5, 77-82, 2008.

[14] Francisca I. A., Maria I. F. G., Ícaro G. P. V., Francisca N. P. M., Paula A. S. R., Carla S.C. M., Maria M. M. Á. and Luzara M. R., "Determination of synthetic food dyes in commercial soft drinks by TLC and ionpair HPLC", Food Chemistry,http:// dx.doi. org/ 10.1016/ j.foodchem. 01.100, 2014.

[15] Purkait M. K., Banerjee S., Mewara, S., DasGupta S. and De S., "Cloud point extraction of toxic eosin dye using Triton $\mathrm{X}-100$ as nonionic surfactant", Water Res., 39, 3885-3890, 2005.

[16] Narumol V., Juthamas M. and Wonn op V., "Identification and Determination of Seven Synthetic Dyes in Foodstuffs and Soft Drinks on Monolithic C18 Column by High Performance Liquid Chromatography", J. Food and Drug Anal., 16, 5, 77-82, 2008.

[17] Laurian V., Dana A., Simona C., and Lorena F., "Developed and validation of an HPLC-UV method for determination of synthetic food colorant", Rev. Roum. Chim., 59(9), 719-725, 2014.

[18] Feng., Yansheng Z., Wei Y., Li S., Guibin J. and Xiaogang C., "Highly sensitive and accurate screening of 40 dyes in soft drinks by liquid chromatography-electrospray tandem mass spectrometry", J. Chromatography, 879, 1813-1818, 2011.

[19] Aslihan K., Cagri A. and Mustafa S., "Solid-phase extraction of some food dyes on sea sponge column and determination by UV-Vis spectrophotometer", Desalination and Water Treatment, 1- 8, 2016.

[20] Frederic M., Jean-Marie O., Marco M. and Caroline M., "Determination of 18 water-soluble artificial dyes by LC-MS in selected matrices", Food Chemistry, 197, 1249-1255, 2016.

[21] Fatma T. and Mahmure U., "Simultaneous Determination of Allura Red and Ponceau 4R in Drinks with the Use of Four Derivative Spectrophotometric Methods and Comparison with HighPerformance Liquid Chromato-graphy", J. AOAC Int., 96, 6, 1377-1386, 2013. 